Canadian

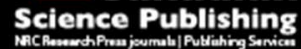

Canadian Journal of Microbiology Revue canadienne de de microbiologie

\title{
Analysis of biofilm formation by intestinal lactobacilli
}

\begin{tabular}{|c|c|}
\hline Journal: & Canadian Journal of Microbiology \\
\hline Manuscript ID: & cjm-2015-0007.R1 \\
\hline Manuscript Type: & Article \\
\hline Date Submitted by the Author: & 01-Apr-2015 \\
\hline Complete List of Authors: & $\begin{array}{l}\text { Slizova, Magdalena; University of veterinary medicine and pharmacy, } \\
\text { Microbiology and immunology } \\
\text { Nemcova, Radomira; University of Veterinary Medicine and Pharmacy, } \\
\text { Department of Microbiology and Immunology } \\
\text { Madar, Marian; University of veterinary medicine and pharmacy, } \\
\text { Microbiology and immunology } \\
\text { Hadryova, Jana; University of veterinary medicine and pharmacy, } \\
\text { Microbiology and immunology } \\
\text { Gancarcikova, Sona; University of veterinary medicine and pharmacy, } \\
\text { Microbiology and immunology } \\
\text { Popper, Miroslav; University of veterinary medicine and pharmacy, } \\
\text { Microbiology and immunology } \\
\text { Pistl, Juraj; University of veterinary medicine and pharmacy, Microbiology } \\
\text { and immunology }\end{array}$ \\
\hline Keyword: & biofilm, Lactobacillus, probiotic, GIT, FISH \\
\hline
\end{tabular}


1 Analysis of biofilm formation by intestinal lactobacilli

2 Magdaléna Slížová, Radomíra Nemcová*, Marián Mad’ar, Jana Hadryová, Soňa

3 Gancarčíková, Miroslav Popper, Juraj Pistl

4 University of Veterinary Medicine and Pharmacy, Komenského 73, 04181 Košice, Slovak

$5 \quad$ Republic

6

7 Magdaléna Slížová, Ing.: magdalenaslizova@gmail.com

$8 \quad$ Radomíra Nemcová, Assoc. Prof., PhD: radomira.nemcova@uvlf.sk

$9 \quad$ Marián Mad'ar, DVM, PhD: madarmarian@gmail.com

10 Jana Hadryová, RNDr.: janny.hadryova@gmail.com

11 Soňa Gancarčíková, DVM, PhD: sona.gancarcikova@gmail.com

12 Miroslav Popper, DVM: miro.popper@gmail.com

13 Juraj Pistl, Prof., PhD: Juraj.Pistl@uvlf.sk

14

*Corresponding author: Radomíra Nemcová Assoc. Prof., PhD, Department of Microbiology and Immunology, University of Veterinary Medicine and Pharmacy, Komenského 73, 04181

Košice, Slovak Republic, E-mail: radomira.nemcova@uvlf.sk, Tel.: +421907919525 
52

\section{Abstract}

In this study, biofilm forming potential of intestinal Lactobacillus reuteri strains under different culture conditions was characterized by microtiter plate biofilm assays. Moreover, the spatial organization of exogenously applied L. reuteri L2/6 (a pig isolate) at the specific locations in gastrointestinal tract of monoassociated mice was investigated by FISH. We did not detect biofilm formation by tested strains in nutrient-rich MRS medium. On the contrary, a highly positive biofilm formation was observed in medium with lower accessibility to the carbon sources and lack of salts. The results obtained confirmed the significant role of Tween 80 and the quantity and nature of the sugars in the growth medium on biofilm formation. The omission of Tween 80 in MRS medium favored the formation of biofilm. Abundant biofilm formation was detected in the presence of lactose, galactose and glucose. However, gradual increase in sugars concentration triggered significant decrease in biofilm formation. In addition, conditions related to the gastrointestinal environment such as low $\mathrm{pH}$, the presence of bile and mucins highly modulated biofilm production. This effect seems to be dependent on the specificity and properties of the medium used for cultivation. From the evidence provided by this study we conclude that the biofilm formation capacity of L. reuteri is strongly dependent on the environmental factors and culture medium used.

Key words: biofilm, Lactobacillus, probiotic, GIT, FISH 
Introduction

The use of probiotics in the prevention and treatment of diarrheal diseases has been proposed for many years (Corcionivoschi et al. 2010). The Lactobacillus species found in the gastrointestinal tract (GIT) have received an important attention due to the possession of health-promoting properties. They are commonly used as probiotics, which according FAO/WHO are defined as live microorganisms, and when administered in adequate amounts confer a health benefits to the host. The proposed mechanism of probiosis include effects on composition, diversity and function of the intestinal microbiota by competition for the nutrients, production of growth substrates or inhibition and modulation of intestinal immunity (Preidis and Versalovic, 2009; Thomas and Versalovic, 2010). Preidis et al. (2012) demonstrated a transient increase in phylogenetic diversity and evenness between taxa of the fecal microbiome in mice $24 \mathrm{hrs}$ after a single probiotic L. reuteri gavage. The diversity in microbial communities was shown to be associated with increased ecological stability (Eisenhauer et al. 2012).

One of the frequently exploited activities used to screen probiotic candidates is adhesion to the mucus and epithelial cells or co-aggregation what is presumed to be essential for the immune modulation, pathogen exclusion and enhanced contact with the gut mucosa (Ouwehand et al. 2002). In order to study the process of adhesion a variety of methods for the quantitative measurement of adhesion such as quantitative culturing, radioactive labeling, fluorescence in situ hybridization - FISH (Bernet et al. 1993; Mack et al. 1999; Mare et al. 2006), or in vitro model systems e.g. immobilized mucus models and cell-culture models (Tuomola et al. 1998; Jonsson et al. 2001; Li et al. 2008) have been developed. However, most studies show that probiotic lactobacilli do not permanently colonize GIT and are beneficial to the hosts only for a brief periods after they have stopped being administered (Tannock et al. 2000; Garrido et al. 2005). 
Bacteria of the genus Lactobacillus in mice, rats, chickens and pigs are clearly autochthonous to the proximal GIT regions (Tannock 1992; Walter 2005a). The epithelial associations formed by lactobacilli in parts of the stomach, esophagus and crop show characteristics typical for the bacterial biofilms formation (Abee et al. 2011). These bacteria are firmly adhered to the surface of nonglandular, squamous stratified epithelium and embedded in a self-produced matrix of extracellular polymeric substance (Tannock et al. 2005; Walter et al. 2007). From an ecological point of view, living in a biofilm is a selective advantage that allows microbes to live in a protected niche allowing to interact directly with the host, and to prolong their survival in the GIT with higher metabolic and beneficial efficiency (Macfarlane 2008; Jones and Versalovic 2009). The findings suggest that several genetic and environmental factors influence the formation of these microbial structures within the GIT (Lebeer et al. 2007; Monds and O'Toole 2009). The numbers of hierarchically ordered genetic factors control the temporal development of biofilm formation and these genetic switches are normally activated in response to the changes of external stimuli i.e. shear stress, microbe-microbe interactions, presence of oxygen, host-microbe interactions (Marzorati et al. 2011).

Lactobacillus reuteri, a large component of GIT biofilm, has been very frequently used to identify bacterial factors that allow lactobacilli to persist in the GIT. Its genome harbor many genes encoding large cell surface proteins putatively involved in adhesion to the epithelium and biofilm formation (Walter et al. 2011; Frese et al. 2011). The cell surface proteins MucBP and Lar 0958 are involved in binding of $L$. reuteri to the mucus (Roos and Jonsson 2002; MacKenzie et al. 2010; Etzold et al. 2014). A large surface protein (Lsp) binding to the epithelium of forestomach have also been functionally characterized (Walter et al. 2005b). The EPS-producing enzymes, GtfA and Inu, of L. reuteri TMW1.106 have been shown to contribute to the cell aggregation, in vitro biofilm formation and colonization of the 
mouse gastrointestinal tract (Walter et al. 2008; Sims et al. 2011). L. reuteri also transcribed with high frequency genes encoding pathways enhancing acid tolerance (urea degradation, arginine pathway, $\gamma$-aminobutyrate) and oxidative stress (glutathione synthesis) (Walter et al. 2011; Su et al. 2011, 2012). In addition, expression of pathways modifying the structure of the bacterial cell wall (DltA, cyclopropane-fatty-acyl-phospholipid synthase) had been correlated with acid resistance (Schwab et al. 2014). Walter et al. (2007) inactivated the dltA gene of $L$. reuteri 100-23 and consequently observed the reduction in strain competitiveness in vivo. Nevertheless the adherence was not affected. The LysM/YG proteins of L. reuteri show characteristics of proteins that can induce aggregation in lactobacilli, possibly by the Nterminal LysM domain binding to the peptidoglycan and C-terminal YG-motif to carbohydrate moieties (Frese et al. 2013).

Comparative genomics revealed that the evolution of L. reuteri resulted in hostconfined phylogenetic lineages with a specialization to the particular hosts (Oh et al. 2010; Frese et al. 2011). Analyses performed suggest a fundamentally different genome evolution in the rodent isolate L. reuteri 100-23 and human isolate L. reuteri F275 (Frese et al. 2011). The ability of L. reuteri 100-23 to form epithelial biofilms in the mouse forestomach is strictly dependent on the strain's host origin. The host specificity of this strain appears to be mediated by a serine-rich surface adhesin Lr70902 (Fap1-like protein) (Frese et al. 2013). Genome hybridization revealed that the sourdough isolate L. reuteri LTH2584 model had genome content very similar to that of model rodent isolate 100-23. Transcripts for the proteins that assured competitiveness of $L$. reuteri in cereal fermentation were also highly transcribed in biofilms, what corroborated with the proposed model of shared intestinal origin for the rodent and sourdough isolates (Su et al., 2012). These observations strengthen the importance of habitat adaption when selecting lactobacilli for the health applications e. g. appropriate use of probiotics. 
of intestinal lactobacilli strains in vitro and subsequently investigates the spatial organization

132 of exogenously applied L. reuteri L2/6 (a pig isolate) at specific locations in the gastrointestinal tract of monoassociated mice

134

135
.Materials and methods

Micro-organisms and growth conditions

The strains of lactobacilli, used in the present study, were isolated in our Laboratory from the gut contents of healthy suckling piglets and pheasants. In the previous study the strains were identified by Maldi-Tof MS bacterial identification as Lactobacillus reuteri: L2/6, B2/1, B10/1, B1/1 and L26. The strains were characterized by inhibitory activity against pathogenic strains in vitro and by production of exopolysaccharides (Ryznerová 2013). Lactobacilli were routinely grown at $37^{\circ} \mathrm{C}$ in de Man-Rogosa-Sharpe agar (MRS; Carl Roth $\mathrm{GmbH}+\mathrm{CO} . \mathrm{KG}$, Karlsruhe, Germany). Plates were incubated anaerobically (Gas Pak Plus, BBL Microbiology systems, Cockeysville, USA) at $37^{\circ} \mathrm{C}$ for $48 \mathrm{~h}$.

Genotypic identification of strains

Amplification of DNA was carried out using of species-specific primers: L-reu-1f (5-

CAGACAATCTTTGATTGTTTAG-3) and L-reu-1r 5-CTTGTTGGTTTGGGCTCTTC-3 according to Dommels et al. (2009) and Garg et al. (2009). Aliquots of the PCR products were separated by horizontal $1 \%$ agarose gel electrophoresis in TAE buffer $\mathrm{pH} 7.8$ (40 mM Tris, $20 \mathrm{mM}$ acetic acid, $1 \mathrm{mM}$ EDTA). A 100-bp DNA ladder (BioLabs, UK) was used as a reference. Gel was stained with GoodView ${ }^{\mathrm{TM}}$ and visualized under UV light. For a positive control Lactobacillus reuteri DSM 17938 strain (BioGaia AB, Sweden) was used. 
In vitro biofilm assay

The culture media assayed were standard MRS and modified PYG (peptone yeast glucose) broths. PYG broth, by contrast to MRS medium, contains the lower amount of glucose and no salts. Consists of (g/l): 15, bacteriological peptone; 5 , enzymatic digest of casein; 10, glucose; 10, yeast extract, $\mathrm{pH}$ 6.5. Other compounds tested in this study were: Tween 80, glucose, sucrose, lactose, fructose, mannose, galactose, mucin from porcine stomach type III and bile (bovine, minimum 50\% bile acids, mixture of free and conjugated bile acids, Sigma). The $\mathrm{pH}$ of the media was adjusted with $1.0 \mathrm{M} \mathrm{HCl}$ or $1.0 \mathrm{M} \mathrm{NaOH}$ before autoclaving. One colony of the strain was transferred to a $5 \mathrm{ml}$ of appropriate broth and incubated for $18 \mathrm{~h}$ at $37{ }^{\circ} \mathrm{C}$. Then the culture was centrifuged $(10000 \mathrm{x} \mathrm{g}, 10 \mathrm{~min})$, and the sediment was resuspended in phosphate-buffered saline (PBS; $\mathrm{g}^{-1}: 8 \mathrm{NaCl}, 0.0002 \mathrm{KCl}, 1.15$ Na2HPO4, 0.2 KH2PO4; $\mathrm{pH}$ 7.4) to reach the McFarland standard 1 suspension that corresponded to $1 \times 10^{8} \mathrm{CFU} \mathrm{ml}^{-1}$. A modified version of a previously described method O'Toole et al. (1999) was used for assaying biofilm formation. A volume of $200 \mu 1$ of the culture was inoculated in a well of a polystyrene microtitre plate (Greiner ELISA 8 Well Strips, 350 $\mu$, Flat Bottom, Medium Binding; Cruinn Diagnostics Ltd., Dublin, Ireland) and incubated without shaking for $72 \mathrm{~h}$ at $37^{\circ} \mathrm{C}$. The biofilm formed in the well of the microtitre plate was washed five times with $200 \mu \mathrm{l}$ of PBS and dried at $25{ }^{\circ} \mathrm{C}$ for $40 \mathrm{~min}$ in an inverted position. The remaining attached bacteria were stained for 30 min at $25{ }^{\circ} \mathrm{C}$ with $200 \mu 10.1 \%$ $(\mathrm{W} / \mathrm{V})$ crystal violet in an isopropanol-methanol-PBS solution $(1: 1: 18 \mathrm{~V} / \mathrm{V})$. The dye solution was aspirated away, and the well was washed five times with $200 \mathrm{ml}$ of distilled water. After water removal and drying for $30 \mathrm{~min}$ at $25{ }^{\circ} \mathrm{C}$ the dye bound to the adherent biofilm was extracted with $200 \mu \mathrm{l}$ of the ethanol - acetone $(80: 20, \mathrm{~V} / \mathrm{V})$ mixture. Aliquot of $150 \mu 1$ from each well were taken and placed in a different microplate for OD determination at $570 \mathrm{~nm}$ using a Synergy ${ }^{\text {TM }} 4$ Multi-Mode Microplate Reader (BioTek, USA). Each strain and/or 
condition was tested in three independent experiments with eight biological replicates. Additionally, a sterile culture medium was always included as negative control to ensure that the influence on biofilm formation by mucin, and bile was not attributed to a nonspecific binding effect to crystal violet. Biofilm formation was categorized as highly positive $\left(\mathrm{OD}_{570} \geq\right.$ 1), low-grade positive $\left(0.1 \leq \mathrm{OD}_{570}<1\right)$, or negative $\left(\mathrm{OD}_{570}<0.1\right)$ (Chaieb et al. 2007). Animals and experimental design

The State Veterinary and Food Administration of the Slovak Republic approved the experimental protocol number 2860/12-221 for germ-free mice. The animals were handled and sacrificed in a humane manner in accordance with the guidelines established by the respective commission. Four-week-old female BALB/c germ-free mice were provided by the Institute of Microbiology, Nový Hrádok, Czech Republic. The mice were housed in gnotobiotic isolator for breeding of laboratory mice THF type 3271 101/97 (Ehret, Germany). Animals had continuous access to distilled autoclaved water in glass bottles and were fed ad libitum with complete sterile feed mixtures for mice holdings ST-1 (Velaz, Praha, Czech Republic). Twenty animals were divided into two groups. Experimental group was fed daily with $0.1 \mathrm{ml}$ of strain Lactobacillus reuteri L2/6 containing $1 \times 10^{9} \mathrm{CFU} / \mathrm{ml}$ of bacteria by means of an intragastric feeding needle for a period of 14 days. Control group received $0.1 \mathrm{ml}$ of sterile saline solution. At Day 14 mice were euthanized by sodium pentobarbital (86 $\mathrm{mg} / \mathrm{kg}$ ) followed by cervical dislocation. The GIT was aseptically removed and divided into sections consisting of stomach, duodenum and caecum.

Fluorescence in situ hybridization analysis

Samples of stomach, duodenum and caecum with contents were fixed immediately in Carnoy's solution for $4 \mathrm{hrs}$ at $4^{\circ} \mathrm{C}$ to preserve the mucus layer. Prior to FISH analysis, serial paraffin sections of $7 \mu \mathrm{m}$ thickness were placed on positively charged slides (SuperFrost Plus, Braunschweig, Germany). FISH was performed as described by Lebeer et al. (2011). 
205 Enzymatic mixture and hybridization buffer were used according to Czerwinski et al. (2012).

206 For detection of Lactobacillus spp. probe Lab158 was used. Labeling was performed with 207 TxRd (Texas red; sulforhodamine 101 acid chloride). Probe was HPLC purified and 208 synthesized by Sigma Aldrich. For hybridization a probe at concentration $100 \mu \mathrm{M}$ diluted in 209 ratio 1:25 into hybridization buffer was used. The hybridization was carried out overnight at $21052^{\circ} \mathrm{C}$ in hybridization humid chamber. Samples were also stained with 4 ', 6-diamidino-2 211 phenylindole (DAPI) dye in concentration $2 \mu 11^{-1}$ during $10-15 \mathrm{~min}$ at $25^{\circ} \mathrm{C}$ for visualization 212 of the other possible contaminant bacteria and tissue cells present in histological sections.

213 Dried section slices were covered by long coverslips with Vectashield mounting medium to 214 prevent photobleaching (Vector Laboratories, UK). The tissue sections were visualized by 215 epifluorescence microscopy with Carl Zeiss Axio Observer Z1 microscope and images were 216 analyzed with AxioVision Rel.4.6 software (Carl Zeiss, Belgium). For detection of probe 217 Lab158 labeled with TxRd (excitation at 587nm and emission 647-670 nm - red color) filter 218 set 64HE was used. To visualize tissue cells labeled with DAPI (excitation at $365 \mathrm{~nm}$ and 219 emission at 445-450 $\mathrm{nm}$ - blue color) filter set 49 was used.

220 Statistical analysis

221 Data were analyzed with GraphPadPrism version 3.00 (GraphPad Software, San Diego California USA, www.graphpad.com.) by one-way analysis variance (ANOVA) followed by Tukey's multiple comparison test.

Results and Discussion

227 bacteria form multicellular matrix consisting of a mixture of polymeric compounds including 228 extracellular DNA, proteins and polysaccharides. Depending on the type of microorganisms, 
age of biofilms and environmental conditions the EPS are main components determining the architecture of bacterial biofilms (Vu et al. 2009; Branda et al. 2005).

Microorganisms growing in biofilm frequently express phenotypes that are different from their nonadherent counterparts. For example, biofilm formed by lactobacilli cells exhibit greater resistance to the acetic acid and ethanol when compared to the planktonic cells (Kubota et al. 2008). Biofilm-growing probiotic strains have the ability to contribute to the enhanced thermotolerance and freeze-drying resistance (Cheow and Hadinoto 2013). Lactobacillus reuteri produce biofilms that retain functions potentially advantageous to the host such as modulation of cytokine output and production of antimicrobial agent reuterin (Jones and Versalovic 2009). When compared with the extensive studies performed on the biofilm formation of several microbial pathogens the factors and mechanisms controlling biofilm formation of probiotic bacteria have been so far poorly investigated. In fact, these above cited studies can provide insights how normal microbiota is maintained, what is a starting point and key for rational use of probiotics.

Several studies reported about the role of EPS production in biofilm formation by lactic acid bacteria. The EPS was described as a promoting factor for the intracellular interactions, autoaggregation and formation of microcolonies depending on the cellular and environmental conditions (Sturme et al. 2005; Lebeer et al. 2007, 2008; Walter et al. 2008a; Sims et al. 2011; Dertli et al. 2015). Strains of Lactobacillus reuteri can produce glucans and fructans of different linkage types (Kralj et al. 2004; Tieking et al., 2005; van Hijum et al., 2002, 2006). These compounds are synthesized from sucrose by a single action of extracellular enzymes termed glycosyltransferases, or in particular by glucosyltransferases and fructosyltransferases. Schwab et al. (2007) indicated that the impact of different glycosyltransferases on sucrose metabolism of $L$. reuteri is strain dependent and can be affected by the competitiveness of some L. reuteri strains in ecosystems where sucrose is 
254 present. In strain L. reuteri TMW 1.106, GtfA accounts for sucrose utilization, metabolism, 255 and growth of the organism. In contrast, FtfA of L. reuteri LTH5448 contributes to the 256 sucrose turnover but alternative routes for sucrose metabolism are also functional for this 257 strain.

Preliminary, in vitro investigations have shown that carbohydrate molecules are likely to be involved in biofilm formation by lactobacilli, while surface protein appears to initiate the adherence in vivo (Walter et al., 2005b; Frese et al. 2013). For example, it was reported that biofilm formation by L. reuteri TMW1.106 on glass surface was reduced after deletion of the gtf and $f t f$ genes in comparison to wild type strain. However, the in vivo analysis of biofilm formation on forestomach epithelial cells revealed that there was no significant difference in biofilm formation properties of mutant or wild type strains (Walter et al., 2008b). In L. reuteri 100-21 the ftf mutant was able to form biofilms, on the forestomach epithelial surface, comparable to wild type strain (Sims et al. 2011). Biofilm formation analysis in L. rhamnosus GG demonstrated that EPS can be involved in this process but the effect of EPS on biofilm formation was more likely medium dependent (Lebeer et al. 2007). The level of EPS production as well as the structural composition can play a role in process of biofilm formation (Vu et al. 2009). Leber et al. (2007) observed increased L. rhamnosus GG biofilm formation by inulin due to stimulation of aggregation. These complex polysaccharides might be incorporated in the extracellular matrix, thereby enhancing biofilm formation.

To advance our understanding of how environmental factors may modify probiotic biofilm formation the EPS producing strains of Lactobacillus reuteri, isolated from the gut contents of healthy suckling piglets and pheasants, was tested. We determined how culture medium, some medium compounds and GIT simulated conditions ( $\mathrm{pH}$, bile, and mucin) may possibly influence biofilm formation. The strains subjected to the PCR analysis with speciesspecific primers for Lactobacillus reuteri (L-reu-1f and L-reu-1r) gave positive $\sim 300 \mathrm{bp}$ 
amplicons (Fig. 1) what confirmed results obtained by Maldi-Tof MS from our previous study (Ryznerová 2013). Biofilm forming capacity was assessed with crystal violet dye, the standard stain for evaluation of biofilms formation (O'Toole et al. 1999). Crystal violet provides a good detection of biofilm mass. However, this dye does not identify biofilm viability due to the labelling both; the bacterial cells and extracellular matrix (Welch et al. 2012).

In tested strains of lactobacilli we have compared the capacity of biofilm formation in two culture media: the standard medium for lactobacilli (nutrient-rich MRS medium) and PYG medium (differs from MRS by lower availability of carbon sources and by salts deficiency). Strains showed similar rates of planktonic growth in the media used in the biofilm assay (data not shown). Fig. 2 shows production of biofilm by Lactobacillus reuteri strains in MRS broth and PYG broth under aerobic conditions. We did not detect biofilm formation of all tested strains in MRS broth. The absorbance levels were below 0.1 what were identical with negative controls readouts. Highly positive biofilm formation $\left(\mathrm{OD}_{570} \geq 1\right)$ was observed after $72 \mathrm{~h}$ incubation in PYG medium with lower availability of carbon sources and deficient in salts. However, the biofilm formation was different between the particular strains tested $(p<0.001 ; p<0.01)$. Similar variability in biofilm formation on abiotic surfaces was also observed by Emanuel et al. (2010) in L. rhamnosus, Lebeer et al. (2007) in L. rhamnosus a L. casei, Jones a Versalovic (2009) in L. reuteri, and Ibarreche et al. (2014) in L. sakei a L. curvatus strains. We found that the quantity and nature of the sugars in the growth medium influenced biofilm formation in tested lactobacilli (Fig. 3). L. reuteri L2/6 strain formed biofilms in the presence of all tested sugars. However, L. reuteri B10/1 strain did not form biofilm in the presence of sucrose. Highly positive biofilm formation $\left(\mathrm{OD}_{570} \geq 1\right)$ was detected in the presence of lactose, galactose and glucose. The presence of fructose and mannose 
resulted in less sizeable biofilm formation $\left(0.1 \leq \mathrm{OD}_{570}<1\right)$. Gradual increase in sugars concentration instigated significant decrease in biofilm formation $(P<0.001 ; P<0.01$; Fig. 4). Several factors including sugar metabolism may lead to the modified biofilm formation (Jin et al. 2004; Chai et al. 2012; Cai et al. 2013). In line with work presented here, L. rhamnosus GG and vaginal lactobacilli were not able to form biofilm after 24 or $96 \mathrm{~h}$ culture in standard culture media used for lactic acid bacteria where polystyrene microplates were used (Lebeer et al. 2007, Terraf et al. 2012). More likely this ability depends on the different strains and environmental factors involved. Martín et al. (2008) showed that vaginal L. jensenii strains adhere strongly to the plastic substrate in standard MRS medium. Variations in availability of fermentable carbon and $\mathrm{C} / \mathrm{N}$ ratio can also modulate biofilm formation. Lack of carbon sources in MRS medium (e.g. omission of glucose or supplementation of lactose or sucrose) as well as of divalent cations (e.g. omission of MnSO4), which can affect bacterial adhesion, did not stimulate biofilm development by vaginal lactobacilli (Terraf et al. 2012). On the other hand, L. rhamnosus GG formed biofilm in modified TSB medium (Trypticase soy broth) with low $\mathrm{C} / \mathrm{N}$ ratio and when glucose and MnSO4 were absent in MRS broth. However, no biofilm formation was evidenced in glucosedepleted MRS by L. rhamnosus and L. casei strains (Lebeer et al. 2007). In L. johnsonii FI9785 the omission of glucose and low relative ratio of $\mathrm{C} / \mathrm{N}$ in growth medium reduced the biofilm formation. The suppressive effect of glucose may be medium dependent or strain specific. The removal of salts solution containing $\mathrm{Mn} 2+$ and $\mathrm{Mg} 2+$ from the MRS medium significantly reduced biofilm formation of L. johnsonii FI9785 and its mutants possibly due to the important role of these metal ions in cell metabolism (Dertli et al. 2013).

Our next analysis focused on the effect of Tween 80 on biofilm formation (Fig. 3) where Tween 80 , a nonionic surfactant and source of fatty acids, was absent in the MRS medium. Additionally, the effect of this component was investigated after its addition to PYG 
medium in the same concentration as found in MRS medium. The omission of Tween 80 from MRS medium favored the formation of biofilm $(\mathrm{p}<0.001)$ by L. reuteri strains. Nevertheless, the biofilm formation was less distinct in MRS medium without Tween 80 when compared with standard PYG medium. Biofilm-repressing effect of Tween 80 was confirmed by addition of this component to PYG medium what resulted in significant reduction $(\mathrm{p}<0.001)$ of biofilm formation. In agreement with our results Terraf et al. (2012) reported that the omission of Tween 80 surfactant in the standard culture media favored the formation of biofilm by biofilm forming vaginal lactobacilli. Nevertheless, the effect of Tween 80 appears to be medium and strain specific. Its omission does not seem to be sufficient to induce biofilm formation induced by L. johnsonii FI9785. In general, salts solution composition appeared to be more effective than Tween 80 on biofilm formation by L. johnsonii FI9785 (Dertli 2013). Biofilm-repressing effect of Tween 80 has not been confirmed in mTSB (modified Trypticase soy broth). The addition of Tween 80 to this medium did not reduce the biofilm formation generated by L. rhamnosus GG (Lebeer et al. 2007).

Formation of biofilms in all tested strains was affected by GIT environmental factors such as low $\mathrm{pH}$, bile and mucin (Fig. 6). In contrast to the neutral $\mathrm{pH}$ low $\mathrm{pH}(\mathrm{pH} 3)$ stimulated biofilm formation $(\mathrm{p}<0.001)$ in L. reuteri $\mathrm{L} 2 / 6$ and L. reuteri $\mathrm{B} 10 / 1$ cultured in MRS $_{\text {-TWEEN }}$ medium and in PYG medium. When compared to controls a significant increase $(p<0.001)$ in biofilm formation after addition of bile at the concentrations of 0.05 and $0.3 \%$ in MRS $_{\text {-TWEEN }}$ medium and $0.05 \%$ in PYG medium was observed. However, increase of bile concentration to $1 \%$, in MRS $_{\text {-TWEEN }}$ medium, markedly decreased biofilm formation ( $\mathrm{p}<0.001$ ) made by L. reuteri L2/6 strain, but did not affect biofilm formation created by $L$. reuteri $\mathrm{B} 10 / 1$. On the contrary a significant decrease $(\mathrm{p}<0.001)$ in biofilm formation was detected in both tested strains where bile concentrations in PYG medium were 0.3 or $1 \%$. The addition of mucin into the MRS $_{\text {-TWEEN }}$ medium, at concentration of $2.5 \mathrm{~g} / 1$, significantly 
353 induced biofilm formation by L. reuteri $\mathrm{L} 2 / 6(\mathrm{p}<0.001)$ and L. reuteri $\mathrm{B} 10 / 1(\mathrm{p}<0.01)$. The 354 effect of mucin seems to be affected by culture medium. Mucin added to the PYG medium 355 did not stimulated biofilm formation.

Based on available literature, bile induced the expression of specific adhesins such as EPS (Hung et al. 2006; Ruas-Madiedo et al. 2009) and fimbria-like appendages (Pumbwe et al. 2007) in some pathogenic and indigenous commensal bacteria. In vitro and in vivo models revealed a correlation between the EPS production and bile tolerance in bifidobacteria. For instance, in B. breve UCC2003, the EPS coat was essential for bile survival and in vivo mice gut colonization (Fanning et al., 2012). Nevertheless, the effect of bile on EPS production in lactobacilli is not well defined yet. Transcriptomic and proteomic data in L. rhamnosus GG point to a reduced production of enzymes involved in EPS biosynthesis in bile-containing environments (Koskenniemi et al. 2011), whereas in L. delbrueckii no variations were found following bile exposure where acquisition of stable bile-resistance correlated with significant overproduction of enzymes involved in EPS biosynthesis (Burns et al. 2010). It still remains to be determined whether bile exposure affects the composition and properties of the EPS layers. Other cell wall structures and characteristics may be affected in response to bile as well. In the case of $L$. acidophilus increased S-layer protein production was detected when cultured in the presence of $0.05 \%$ bile (Khaleghi et al. 2010 Biofilm formation generated by non-autoaggregating strains such as L. plantarum F44, L. paracasei F19 and L. rhamnosus

37218243 grown in MRS broth with $0.5 \%$ taurocholic acid, $5 \%$ porcine bile or $0.25 \%$ mucin, 373 could be correlated with an enhanced cell surface hydrophobicity. These non-autoaggregating 374 strains grown in bile induced the autoaggregating behavior and facilitate biofilm formation 375 (Ambalam et al. 2012). Walter et al. (2008b) investigated the ecological role of a 376 glucosyltransferase (GtfA) and inulosucrase (Inu) of Lactobacillus reuteri TMW1.106 and a 377 fructosyltransferase (FtfA) of L. reuteri LTH5448. In vitro experiments on isogenic mutants 
revealed that GtfA was essential for the sucrose-dependent autoaggregation of $L$. reuteri TMW1.106 cells under acidic conditions, while inactivation of Inu slowed the formation of cell aggregates. Enhanced biofilm formation by Lactobacillus plantarum and Lactobacillus rhamnosus was also noted in a mucin-based medium (Filoche et al. 2004). Therefore the presence of polysaccharides may have a general ability to promote biofilm formation by lactobacilli.

L. reuteri is a gut symbiont colonizing stratified squamous epithelia in the upper intestinal tract of animals and is a stable part of colonic and vaginal microbiota of humans (Reid and Bocking 2003; Walter 2008a; Martín et al. 2008). L. reuteri is also a stable member of sourdough microbiota (De Vuyst et al. 2009). As it has already been mentioned the population genetic analysis and experimental approaches using Lactobacillus-free and monoassociated mouse models revealed that host-specific subpopulations exist among the members of $L$. reuteri species (Frese et al. 2011, 2013; Su et al. 2012; Schwab et al. 2014).

The extensive study Frese et al. (2013) explored the mechanisms that underlie colonization and biofilm formation in specific strains of the gut symbiont Lactobacillus reuteri. The biofilm formation of wild-type strains originated from rodent, human, pig, and chicken were evaluated on monoassociated mouse model. The confocal microscopy analysis confirmed the adherence of rodent strains to the forestomach epithelium and biofilm formation, while non-rodent strains were absent from the stratified squamous epithelium. In contrast to the previous findings on Lactobacillus-free mice (Frese et al. 2011) the non-rodent strains, in the absence of competitive microbiota, were able to colonize the gut lumen of germ-free mice in high numbers. Despite gut colonization these non rodent strains were not able to adhere to the forestomach epithelium or form biofilms. The complete absence of biofilm formation in the $\operatorname{lr} 70902$ mutant strain of rodent L. reuteri 100-23 suggests that this is the adhesion step that confers host specificity. Homologues of Lr70902 can only be found in 
403 rodent and pig isolates of L. reuteri, and these proteins may play a key role in exclusive 404 binding to the epithelium of their respective hosts. The authors in theory suggest that the low 405 sequence similarity between the proteins of rodent and pig strains might be accounted for the 406 observed host specificity.

407

Su et al. (2012) indicated that sourdough isolates of $L$. reuteri emerge from the same

408

409

410

411

412

413

414 phylogenetic line as rodent strains. It was reported that rodent L. reuteri isolates are capable of long-term persistence in food fermentation and that sourdough isolate LTH5448 can colonize the murine gastrointestinal tract of Lactobacillus-free mice and form population sizes comparable to the rodent strain L. reuteri 100-23 (Walter et al. 2008b). Since exLactobacillus-free mice are colonized efficiently only by L. reuteri of rodent origin, the colonization phenotype provides a strong evidence for the intestinal (rodent) origin of this sourdough isolate. Thus, the assignment of sourdough isolates to the intestinal origins does not represent recurrent contamination with raw material by rodent feces. As a consequence and due to the similarities between those two habitats (i.e., availability of carbon source) $L$. reuteri can stably colonize two environmental niches, the upper intestine of mammals that consume cereal-based foods and sourdough ( $\mathrm{Su}$ et al. 2012).

We investigated the spatial organization of exogenously applied non-rodent L. reuteri L2/6 (primarily isolated from the pig gut contents) in stomach, duodenum and caecum of monoassociated mice. Hybridization with Lab158 probe suggested that L. reuteri L2/6 formed biofilm-like structures in mice forestomach (Fig 7). In the duodenum and caecum (Fig 8), mucus ceiling dispersed cells (bacteria in the outer portions of the mucus), occasionally found in small microcolonies appeared to be the colonization form of this strain. Based on the above data we can hypothetically suggest that the examined L. reuteri L2/6 strain isolated from pig's intestine could be originated from cereal-based food and have traits of rodent strains. 
427 However, to confirm this hypothesis, a further investigation utilizing the genomic basis for the 428 strain host specificity is required.

429 The study of factors associated with the production of biofilm will lead to the better 430 understanding of mechanisms by which beneficial bacteria adapt to the stress and colonize 431 natural environment to establish stabile and balanced microbiocenoses. This study provides a 432 preliminary in vitro analysis of biofilm formation by potential probiotic strains of L. reuteri. 433 Biofilm formation appears to be strain specific and modulated to the various extents by 434 environmental factors. Further studies will be performed to understand in better detail the 435 physicochemical and matrix composition properties of L. reuteri, and to identify the mechanisms involved in biofilm formation.

Acknowledgments

We would like to thank Mrs. Silvia Spišáková (The Institute of Parasitology of SAS, Košice) for help with the preparation of histological sections. This publication was supported by the Slovak Research and Development Agency under the contract no. APPVV-0199-11, by the project No. 26220220152 implementation supported by the Research \& Development Operational Programme funded by the ERDF, by the EU Structural Fund ITMS 26220220185 (Medipark) and by the project INFEKTZOON - Centrum of excellences for infectious disease and zoonosis (Operational program of research and development) financed by EU funds for 446 the regional improvement. 
452

453

454

455

456

457

458

459

460

461

462

463

464

465

466

467

468

469

470

471

472

473

474

475

\section{References}

Abee, T., Kovács, A.T., Kuipers, O.P., van der Veen, S. 2011. Biofilm formation and dispersal in Gram-positive bacteria. Curr. Opin. Biotech. 22:172-179.

Ambalam, P., Kondepudi, K.K., Nilsson, I., Wadström, T., Ljungh, A. 2012. Bile stimulates cell surface hydrophobicity, Congo red binding and biofilm formation of Lactobacillus strains. FEMS Microbiol. Lett. 333:10-19.

Bernet, M.F., Brassart, D., Neeser, J.R., Servin, A.L. 1993. Adhesion of human bifidobacterial strains to cultured human intestinal epithelial cells and inhibition of enteropathogen-cell interactions. Appl. Environ. Microbiol. 59:4121-4128.

Branda, S.S., Vik, S., Friedman, L., Kolter, R. 2005. Biofilms: the matrix revisited. Trends Microbiol. 13(1):20-26.

Burns, P., Sanchez, B., Vinderola, G., Ruas-Madiedo, P., Ruiz, L., Margolles, A., et al. 2010. Inside the adaptation process of Lactobacillus delbrueckii subsp. lactis to bile. Int. J. Food Microbiol. 142:132-141.

Cai, W., De La Fuente, L., Arias, C.R. 2013. Biofilm Formation by the Fish Pathogen Flavobacterium columnare: Development and Parameters Affecting Surface Attachment. Appl. Environmen. Microbiol. 79 (18): 5633-564

Chai, Y., Beauregard, P.B., Vlamakis, H., Losick, R., Kolter, R. 2012. Galactose metabolism plays a crucial role in biofilm formation by Bacillus subtilis. MBio. 3(4): 184-12

Cheow, W.S., Hadinoto, K. 2013. Biofilm-like Lactobacillus rhamnosus probiotics encapsulated in alginate and carrageenan microcapsules exhibiting enhanced thermotolerance and freeze-drying resistance. Biomacromol. 14(9): 3214-3222.

Corcionivoschi, N., Drinceanu, D., Pop, I.M., Stack, D., Stef, L., Julean, C., Bourke, B. 2010. The Effect of Probiotics on Animal Health. Anim. Sci. Biotechnol. 43: 35-41. 
Czerwiński, J., Højberg, O., Smulikowska, S., Engberg, R.M., Mieczkowska, A. 2012. Effects of sodium butyrate and salinomycin upon intestinal microbiota, mucosal morphology and performance of broiler chickens. Arch. Anim. Nutr. 66 (2): 102-116.

Dertli, E. 2013. Biochemistry and functional analysis of exopolysaccharide production in Lactobacillus johnsonii. PhD Thesis, 263 p, Institute of Food Research, the University of East Anglia

Dertli, E., Mayer, M.J., Narbad, A. 2015. Impact of the exopolysaccharide layer on biofilms, adhesion and resistance to stress in Lactobacillus johnsonii FI9785. BMC Microbiol. 15:8.

De Vuyst, L., Vrancken, G., Ravyts, F., Rimaux, F., Weckx, S. 2009. Biodiversity, ecological determinants, and metabolic exploitation of sourdough microbiota. Food Microbiol. 26:666-675.

Dommels, Y.E., Kemperman, R.A., Zebregs, Y.E., Draaisma, R.B., Jol, A., Wolvers, D.A., Vaughan, E.E., Albers, R. 2009. Survival of Lactobacillus reuteri DSM 17938 and Lactobacillus rhamnosus GG in the human gastrointestinal tract with daily consumption of a low-fat probiotic spread. Appl. Environ. Microbiol. 75(19): 6198-6204.

Eisenhauer, N., Scheu, S., Jousset, A. 2012. Bacterial diversity stabilizes community productivity. PLoS One 7: e34517. doi: 10.1371/journal.pone.0034517

Emanuel, V., Adrian, V., Diana, P. 2010. Microbial biofilm formation under the influence of various physical-chemical factors. Biotechnol. Equip. 24:1993-1996.

Etzold, S., MacKenzie, D.A., Jeffers, F., Walshaw, J., Roos, S., Hemmings, A.M., Juge, N. 2014. Structural and molecular insights into novel surface-exposed mucus adhesins from Lactobacillus reuteri human strains. Mol. Microbiol. 92:543-556.

Fanning, S., Hall, L.J., Cronin, M., Zomer, A., MacSharry, J., Goulding, D., Motherway, M.O., Shanahan, F., Nally, K., Dougan, G., van Sinderen, D. 2012. Bifidobacterial 
501

502

503

504

505

506

507

508

509

510

511

512

513

514

515

516

517

518

519

520

521

522

523

surface-exopolysaccharide facilitates commensal-host interaction through immune modulation and pathogen protection. Proc. Natl. Acad. Sci. 109(6):2108-2113.

Filoche, S.K., Anderson, S.A., Sissons, CH. 2004. Biofilm growth of Lactobacillus species is promoted by Actinomyces species and Streptococcus mutans. Oral Microbiol. Immunol. 19(5):322-326.

Frese, S.A., Benson, A.K., Tannock, G.W., Loach, D.M., Kim, J., Zhang, M., Oh, P.L., Heng, N.C., Patil, P.B., Juge, N., Mackenzie, D.A., Pearson, B.M., Lapidus, A., Dalin, E., Tice, H., Goltsman, E., Land, M., Hauser, L., Ivanova, N. et al. 2011. The Evolution of Host Specialization in the Vertebrate Gut Symbiont Lactobacillus reuteri. PLoS Genet 7(2): e1001314. doi:10.1371/journal.pgen.1001314

Frese, S.A., MacKenzie, D.A., Peterson, D.A., Schmaltz, R., Fangman, T., Zhou, Y., et al. 2013. Molecular Characterization of Host-Specific Biofilm Formation in a Vertebrate Gut Symbiont. PLoS Genet 9(12): e1004057. doi:10.1371/journal.pgen.1004057

Garg, K.B., Ganguli, I., Das, R., Talwar, G.P. 2009. Spectrum of Lactobacillus species present in healthy vagina of Indian women. Indian J. Med. Res. 129: 652-657.

Garrido, D., Suau, A., Pochart, P., Cruchet, S., Gotteland, M. 2005. Modulation of the fecal microbiota by the intake of a Lactobacillus johnsonii La1-Containing product in human volunteers. FEMS Microbiol. Lett. 248:249-256.

Hung, D.T., Zhu, J., Sturtevant, D., Mekalanos, J.J. 2006. Bile acids stimulate biofilm formation in Vibrio cholerae. Mol. Microbiol. 59:193-201.

Ibarreche, M., Castellano, P., Vignolo, G. 2014. Evaluation of anti-Listeria meat borne Lactobacillus for biofilm formation on selected abiotic surfaces. MEAT Sci. 96:295303. 
524 Jin, Y., Samaranayake, L.P., Samaranayake, Y., Yip, H.K. 2004. Biofilm formation of 525 Candida albicans is variably affected by saliva and dietary sugars. Arch. Oral. Biol. 49: $526 \quad 789-798$.

527 Jones, S.E., Versalovic, J. 2009. Probiotic Lactobacillus reuteri biofilms produce 528 antimicrobial and anti-inflammatory factors. BMC Microbiol. 9: 35-43.

529 Jonsson, H., Ström, E., Roos, S. 2001. Addition of mucin to the growth medium triggers 530 mucus-binding activity in different strains of Lactobacillus reuteri in vitro. FEMS $531 \quad$ Microbiol. Lett. 204:19-22.

532 Khaleghi, M., Kermanshahi, R.K.,Yaghoobi, M.M., Zarkesh-Esfahani, S.H., Baghizadeh, A. 533 2010. Assessment of bile salt effects on s-layer production, slp gene expression and, 534 some physicochemical properties of Lactobacillus acidophilus ATCC4356. J. Microbiol. $535 \quad$ Biotechnol. 20:749-756.

536 Koskenniemi, K., Laakso, K., Koponen, J., Kankainen, M., Greco, D., Auvinen,P., et al. 537 2011. Proteomics and transcriptomics characterization of bile stress response in 538 probiotic Lactobacillus rhamnosus GG. Mol.Cell.Proteomics 10(2):M110.002741. 539 doi:10.1074/mcp.M110.002741

Kralj, S., van Geel-Schutten, G.H., Dondorff, M.M.G., Kirsanovs, S., van der Maarel, M.J.E. C., Dijkhuizen, L. 2004. Glucan synthesis in the genus Lactobacillus: isolation and characterization of glucansucrase genes, enzymes and glucan products from six different strains. Microbiol. 150:3681-3690.

545 lactic acid bacteria and resistance to environmental stress. J. Biosci. Bioeng. 106: 381386. 
547 Lebeer, S., Verhoeven, T.L.A., Velez, M.P., Vanderleyden, J., De Keersmaecker, S.C.J. 2007. 548 Impact of environmental and genetic factors on biofilm formation by the probiotic strain 549 Lactobacillus rhamnosus GG. Appl. Environ. Microbiol. 73(21):6768-6775.

550 Lebeer, S., Vanderleyden, J., De De Keersmaecker, S.C. 2008. Genes and molecules of 551 lactobacilli supporting probiotic action. Microbiol Mol Biol. 72(4):728-764

552 Lebeer, S., Verhoeven, T.L.A., Claes, I.J.J., De Hertogh, G., Vermeire, S., Buyse, J., Van 553 Immerseel, F., Vanderleyden, J., De Keersmaecker, S.C.J. 2011. FISH analysis of 554 Lactobacillus biofilms in the gastrointestinal tract of different hosts. Lett. App. $555 \quad$ Microbiol. 52:220-226.

556 Li, X.J., Yue, L.Y., Guan, X.F., Qiao, S.Y. 2008. The adhesion of putative probiotic 557 lactobacilli to cultured epithelial cells and porcine intestinal mucus. Appl. Microbiol. 558 104:1082-1091.

559

560

561

562

563

564

565

566

567

568

569

570

571

Macfarlane, S. 2008. Microbial biofilm communities in the gastrointestinal tract. J Clin Gastroenterol. 42(3):142-143.

Mack, D.R., Michail, S., Wei, S., McDougall, L., Hollingsworth, M.A. 1999. Probiotics inhibit enteropathogenic $E$. coli adherence in vitro by inducing intestinal mucin gene expression. Am J Physiol 276:941-950.

Mackenzie, D.A., Jeffers, F., Parker, M.L., Vibert-Vallet, A., Bongaerts, R.J., Roos, S., Walter, J., Juge, N. 2010. Strain specific diversity of mucus-binding proteins in the adhesion and aggregation properties of Lactobacillus reuteri. Microbiol. 156:33683378.

Mare, L., Wolfaardt, G.M., Dicks, L.M. 2006. Adhesion of Lactobacillus plantarum 423 and Lactobacillus salivarius 241 to the intestinal tract of piglets, as recorded with fluorescent in situ hybridization (FISH), and production of plantaricin 423 by cells colonized to the ileum. J Appl. Microbiol. 100:838-845. 
572 Martín, R., Soberón, N., Vaneechoutte, M., Flórez, A.B., Vázquez, F., Suárez, J.E. 2008.

573 Characterization of indigenous vaginal lactobacilli from healthy women as probiotic $574 \quad$ candidates. Int. Microbiol. 11:261-266.

575 Marzorati, M., Van den Abbeele, P., Possemiers, S., Benner, J., Verstraete, W., Van de Wiele,

576 T. 2011. Studying the host-microbiota interaction in the human gastrointestinal tract:

577 basic concepts and in vitro approaches. Ann. Microbiol. 61:709-715

578 Monds, R.D., O'Toole, G.A. 2009. The developmental model of microbial biofilms: ten years 579 of a paradigm up for review. Trends Microbiol. 17:73-87.

580 Oh, P.L., Benson, A.K., Peterson, D.A., Patil, P.B., Moriyama, E.N., Roos, S., Walter, J.

5812 2010. Diversification of the gut symbiont Lactobacillus reuteri as a result of host-driven 582 evolution. ISME J. 4:377-387.

583 O’Toole, G.A., Pratt, L.A., Watnick, P.I., Newman, D.K., Weaver, V.B., Kolter, R. 1999. 584 Genetic approaches to study of biofilms. Methods Enzymol. 310: 91-109.

585 Ouwehand, A.C., Salminen, S., Isolauri, E. 2002. Probiotics: An overview of beneficial 586 effects. Antonie Van Leewenhoek 82:279-289.

587 Preidis, G., Versalovic, J. 2009. Targeting the human microbiome with antibiotics, probiotics, 588 and prebiotics: gastroenterology enters the metagenomics era. Gastroenterol. 136:20155892031.

590

591

592

593

594

595

596

Preidis, G., Saulnier, D., Blutt, S., Mistretta, T., Riehle, K., Major, A., et al. 2012. Probiotics stimulate enterocyte migration and microbial diversity in the neonatal mouse intestine. FASEB J 26: 1960-1969.

Pumbwe, L., Skilbecka, C.H.A., Nakano, V., Avila-Camposc, M.J., Piazzad, R.M.F., Wexlera, H.M. 2007. Bile salts enhance bacterial coaggregation, bacterial-intestinal epithelial cell adhesion, biofilm formation and antimicrobial resistance of Bacteroides fragilis. Microb. Pathog. 43:78-87. 
597 Reid, G., Bocking, A. 2003. The potential for probiotics to prevent bacterial vaginosis and $598 \quad$ preterm labor. J. Obstet. Gynecol. 189: 1202-1208.

599 Roos, S., Jonsson, H. 2002. A high-molecular-mass cell-surface protein from Lactobacillus 600 reuteri 1063 adheres to mucus components. Microbiol. 148:433-442.

601 Ruas-Madiedo, P., Gueimonde, M., Arigoni, F., De Los Reyes-Gavilán, C.G., Margolles, A. 602 2009. Bile Affects the Synthesis of Exopolysaccharides by Bifidobacterium animalis. 603 Appl. Environ. Microbiol. 75:1204-1207.

604

605

606

607

608

609

610

611

612

613

614

615

616

617

618

619

Ryznerová, D. 2013. The study of the properties of the probiotic bacteria in terms of their biological effects and applications. Košice, Slovak republic, 148 p (Ph.D. Dissertation, UVMP)

Schwab, C., Walter, J., Tannock, G. W., Vogel, R.F., Ga“nzle, M. G. 2007. Sucrose utilization and impact of sucrose on glycosyltransferase expression in Lactobacillus reuteri. Syst. Appl. Microbiol. 30:433-443.

Schwab, C., Berry, D., Rauch, I., Rennisch, I., Ramesmayer, J., Hainzl, E., et al. 2014. Longitudinal study of murine microbiota activity and interactions with the host during acute inflammation and recovery. The ISME J 8: 1101-1114.

Sims, I.M., Frese, S.A., Walter, J., Loach, D., Wilson, M., Appleyard, K., et al. . 2011. Structure and functions of exopolysaccharide produced by gut commensal Lactobacillus reuteri 100-23. ISME J. 5(7):1115-24.

Sturme, M.H., Nakayama, J., Molenaar, D., Murakami, Y., Kunugi, R., Fujii, T., et al. 2005. An agr-like two-component regulatory system in Lactobacillus plantarum is involved in production of a novel cyclic peptide and regulation of adherence. J Bacteriol. 187(15):5224-5235. 
620 Su, M.S., Schlicht, S., Gänzle, M.G. 2011. Contribution of glutamate decarboxylase in 621 Lactobacillus reuteri to acid resistance and persistence in sourdough. Microb. Cell. Fact.

622

623

624

625

626

627

628

629

630

631

632

633

634

635

636

637

638

639

640

641

642

643

10: S8.

Su, M.S., Phaik, L.O., Walter, J., Gänzle, M.G. 2012. Phylogenetic, genetic, and physiological analysis of sourdough isolates of Lactobacillus reuteri: food fermenting strains of intestinal origin. Appl. Environ. Microbiol. 78:6777-6780.

Tannock, G. W. 1992. Lactic microflora of pigs, mice and rats. In The Lactic Acid Bacteria, vol. 1. The Lactic Acid Bacteria in Health and Disease, 21-48. B. J. B. Wood. London, UK: Elsevier Applied Science.

Tannock, G.W., Munro, K., Harmsen, H.J., Welling, G.W., Smart, J., Gopal, P.K. 2000. Analysis of the fecal microflora of human subjects consuming a probiotic product containing Lactobacillus rhamnosus DR20. Appl. Environ. Microbiol. 66:2578-2588.

Tannock, G.W., Ghazally, S., Walter, J., Loach, D., Brooks, H., Cook, G., Surette, M., Simmers, C., Bremer, P., Dal Bello, F., Hertel, C. 2005. Ecological behavior of Lactobacillus reuteri 100-23 is affected by mutation of the luxS gene. Appl. Environ. Microbiol. 71:8419-8425.

Terraf, M.C., Juárez Tomás, M.S., Nader_Macías, M.E., Silva, C. 2012. Screening of biofilm formation by beneficial vaginal lactobacilli and influence of culture media components. J. Appl. Microbiol. 113(6):1517-1529.

Thomas, C., Versalovic, J. 2010. Probiotics-host communication: modulation of signaling pathways in the intestine. Gut Microbes 1:148-163.

Tieking, M., Kaditzky, S., Valcheva, R., Korakli, M., Vogel, R.F.,Ganzle, M.G. 2005. Extracellular homopolysaccharides and oligosaccharides from intestinal lactobacilli. J. Appl. Microbiol. 99:692-702. 
644 Tuomola, E.M., Salminen, S.J. 1998. Adhesion of some probiotic and dairy Lactobacillus 645 strains to Caco-2 cell cultures. Int J Food Microbiol. 41:45-51.

646 van Hijum, S.A.F.T., van Geel-Schutten, G.H., Rahaoui, H., van der Maarel, M.J.E.C., 647 Dijkhuizen, L. 2002. Characterization of a novel fructosyltransferase from Lactobacillus 648 reuteri that synthesizes highmolecular- weight inulin and inulin oligosaccharides. Appl. $649 \quad$ Environ. Microbiol. 68:4390-4398

650

651

652

653

654

655

656

657

658

659

660

661

662

663

664

665

666

667

van Hijum, S. A. F. T., Kralj, S., Ozimek, L. K., Dijkhuizen, L. \& van Geel-Schutten, G. H. 2006. Structure-function relationships of glucansucrase and fructansucrase enzymes from lactic acid bacteria. Microbiol Mol Biol. 70:157-176.

Vu, B., Chen, M., Crawford, R.J., Ivanova, E.P. 2009. Bacterial Extracellular Polysaccharides Involved in Biofilm Formation. Molecules 14(7):2535-2554.

Walter, J. 2005a. The microecology of lactobacilli in the gastrointestinal tract. In Probiotics and Prebiotics: Scientific Aspects 51-82. G. W. Tannock. Wymondham: Horizon Scientific Press.

Walter, J., Chagnaud, P., Tannock, G.W., Loach, D.M., Dal Bello, F., Jenkinson, H.F., Hammes, W.P., Hertel, C. 2005b. A highmolecular- mass surface protein (Lsp) and methionine sulfoxide reductase $\mathrm{B}(\mathrm{MrsB})$ contribute to the ecological performance of Lactobacillus reuteri in the murine gut. Appl. Environ. Microbiol. 71:979-986.

Walter, J., Loach, D.M., Alqumber, M., Rockel, C., Hermann, C., Pfitzenmaier, M., Tannock, G.W. 2007. D-Alanyl ester depletion of teichoic acids in Lactobacillus reuteri 100-23 results in impaired colonization of the mouse gastrointestinal tract. Environ. Microbiol. 9:1750-1760.

Walter, J. 2008a. Ecological role of lactobacilli in the gastrointestinal tract: Implications for fundamental and biomedical research. Appl. Environ. Microbiol. 74:4985-4996. 
668 Walter, J., Schwab, C., Loach, D.M., Gänzle, M.G., Tannock, ～G.W. 2008 b. 669 Glucosyltransferase A (GtfA) and inulosucrase (Inu) of Lactobacillus reuteri 670 TMW1.106 contribute to cell aggregation, in vitro biofilm formation, and colonization 671 of the mouse gastrointestinal tract. Microbiol. 154(1):72-80.

672 Walter, J., Britton, R.A., Roos, S. 2011. Host-microbial symbiosis in the vertebrate 673 gastrointestinal tract and the Lactobacillus reuteri paradigm. PNAS 108:4645-4652.

674 Welch, K., Cai, Y., Strømme, M. 2012. A Method for Quantitative Determination of Biofilm 675 Viability. J. Funct. Biomater. 3:418-431.

676

677

678

679

680

681

682

683

684

685

686

687

688

689

690

691

692 Figure captions

693 
694 Figure1 Electrophoresis of PCR products obtained with PCR primers L-reu-1f and L-reu-1r.

695 1, DNA Ladder; 2, positive control Lactobacillus reuteri DSM 17938; 3, negative control 696 (without template); 4, strain L2/6; 5, strain B2/1; 6, strain B10/1; 7, strain B1/1; 8, strain L26

697

698 Figure 2 Production of biofilm by Lactobacillus reuteri strains (intestinal isolates) and 699 Lactobacillus reuteri DSM 17938 in MRS and PYG medium.

700

The data are expressed as mean $\mathrm{OD}_{570 \mathrm{~nm}}$ with \pm SEM values. The error bars represent standard 701 deviations of eight biological repeats. The data shown are representative of three independent 702 experiments.

703

704

705

Figure 3 Biofilm formation by of Lactobacillus reuteri L2/6 and B10/1 strains incubated with assorted sugars at $1 \%$ concentration.

706

The data express the mean $\mathrm{OD}_{570 \mathrm{~nm}}$ values $\pm \mathrm{SEM}$. The error bars represent standard 707 deviations of eight biological repeats. The data shown are representative of three independent experiments. Abbreviations used: PYG - glucose; PYS - sucrose; PYL - lactose; PYF fructose; PYM - mannose; PYGAL - galactose.

710

Figure 4 Biofilm formation by of Lactobacillus reuteri L2/6 strain incubated with different sugars concentration.

713 The data express the mean $\mathrm{OD}_{570 \mathrm{~nm}}$ values \pm SEM. The error bars represent standard deviations of eight biological repeats. The data shown are representative of three independent experiments.

717 Figure 5 Production of biofilm by strains Lactobacillus reuteri L2/6 and B10/1 in MRS and 718 PYG medium in the absence or presence of Tween 80. 
719 The data express the mean $\mathrm{OD}_{570} \mathrm{~nm}$ values \pm SEM. The error bars represent standard 720 deviations of eight biological repeats. The data shown are representative of three independent 721 experiments.

722

723

Figure 6 The effect of simulated GIT conditions on biofilm formation by Lactobacillus reuteri

724

725 726

727

728

729

730

731

732

733

734

735

736

737

738

739

740

741
L2/6 and Lactobacillus reuteri B10/1.

The data express the mean $\mathrm{OD}_{570 \mathrm{~nm}}$ values \pm SEM; $\mathrm{MRS}_{\text {-TwEEN }}$ - MRS medium without Tween; PYG - standard PYG medium

Figure 7 Spatial organization of L. reuteri L2/6 in the murine forestomach.

The samples from female BALB/c monoassociated mice were analyzed by FISH after administration of $L$. reuteri L2/6. Lab158 probe was TxRd labelled (red color) and DAPI was used as a counterstain (blue color). Panel A-show bacteria enclosed in an exopolymeric matrix, resembling biofilm-like structures (group with L. reuteri L2/6). Panel B - control group without L. reuteri L2/6. Green color shows autofluorescence of food particles. (100 x)

Figure 8 Spatial organization of L. reuteri L2/6 in the murine duodenum and caecum.

The samples from female BALB/c monoassociated mice were analyzed by FISH after administration of L. reuteri L2/6. Samples of duodenum (A) and caecum (B) were hybridized with the Lab158 probe TxRd labelled (red color). DAPI was used as a counterstain (blue color). Mucus ceiling dispersed cells or microcolony could be observed in the duodenum and caecum. The mucus layer is visible through autofluorescence. 


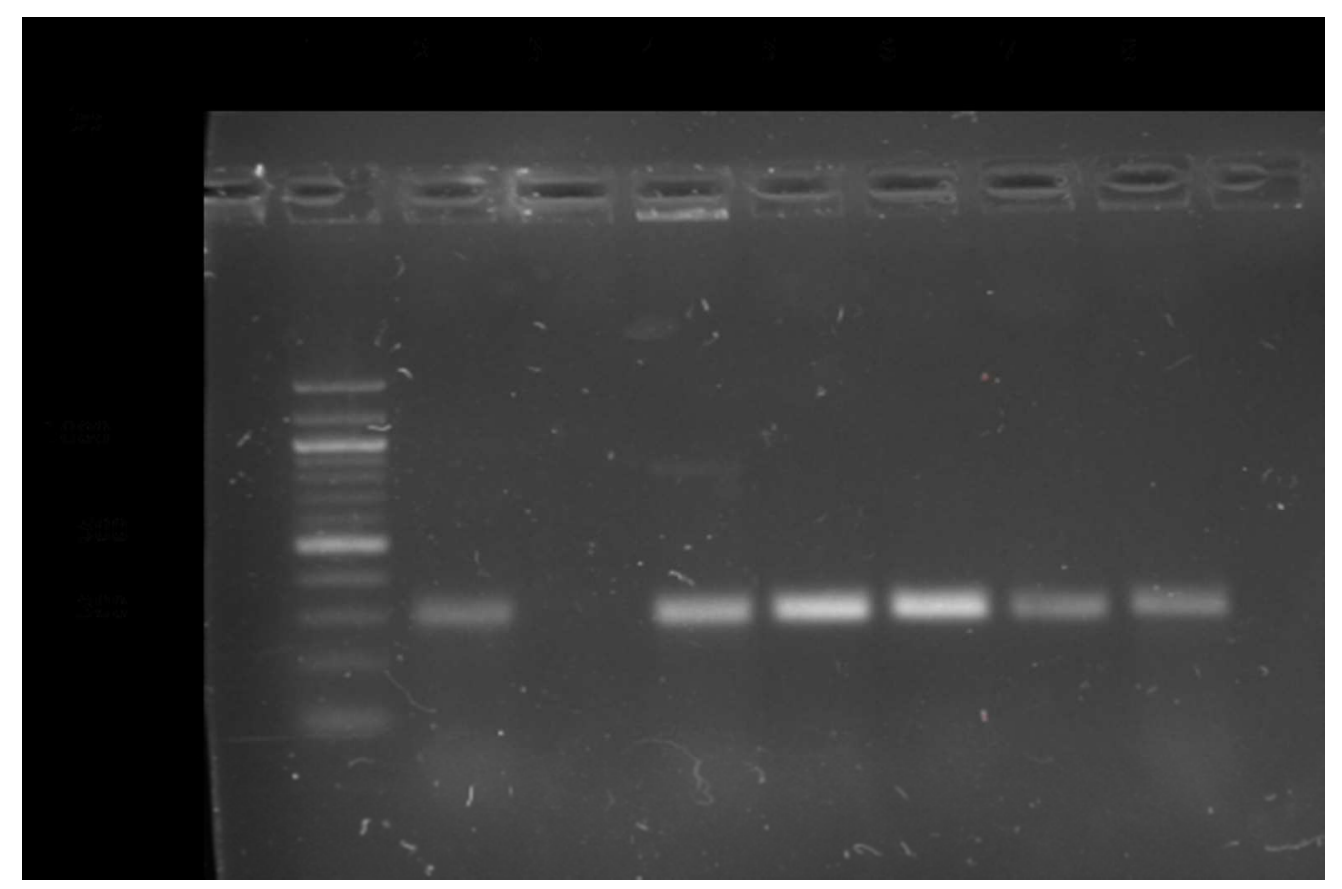

$152 \times 100 \mathrm{~mm}(150 \times 150 \mathrm{DPI})$ 


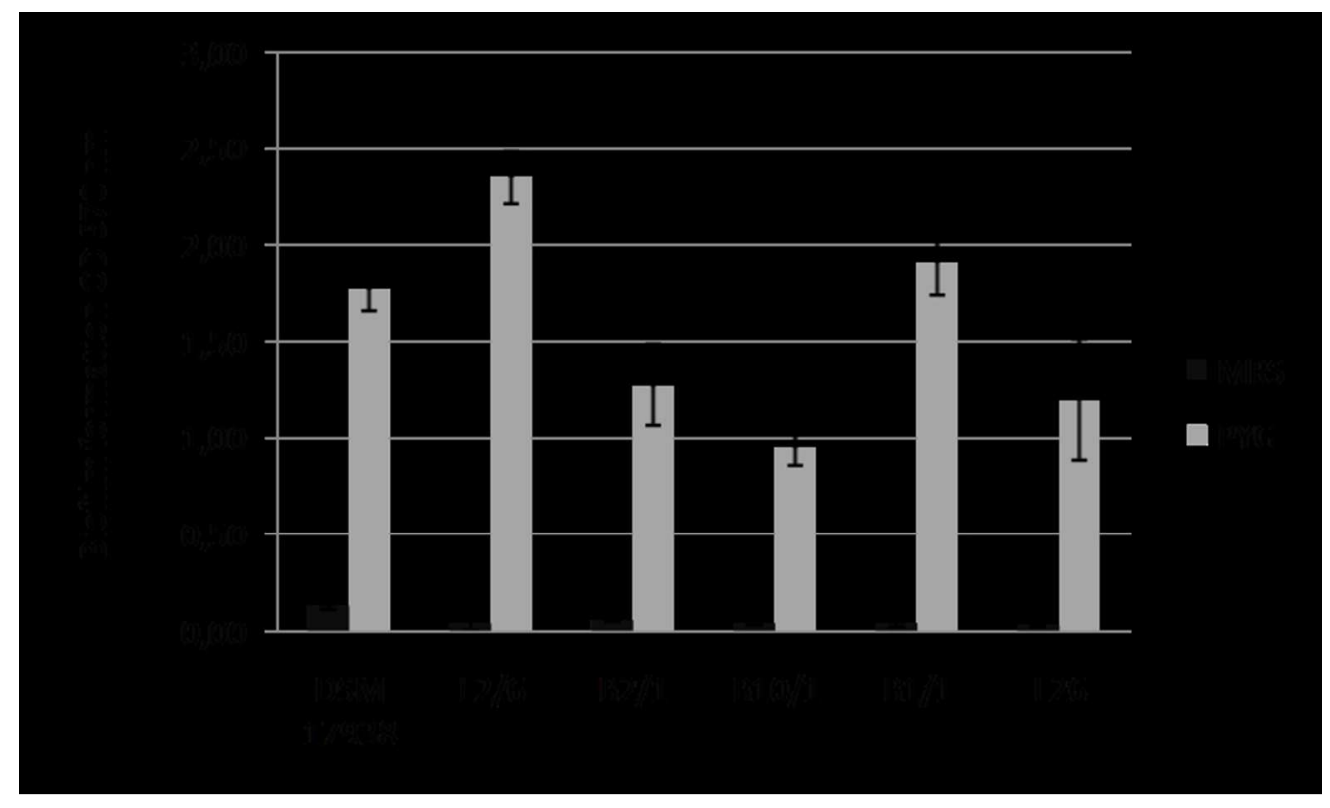

$152 \times 91 \mathrm{~mm}(150 \times 150 \mathrm{DPI})$ 


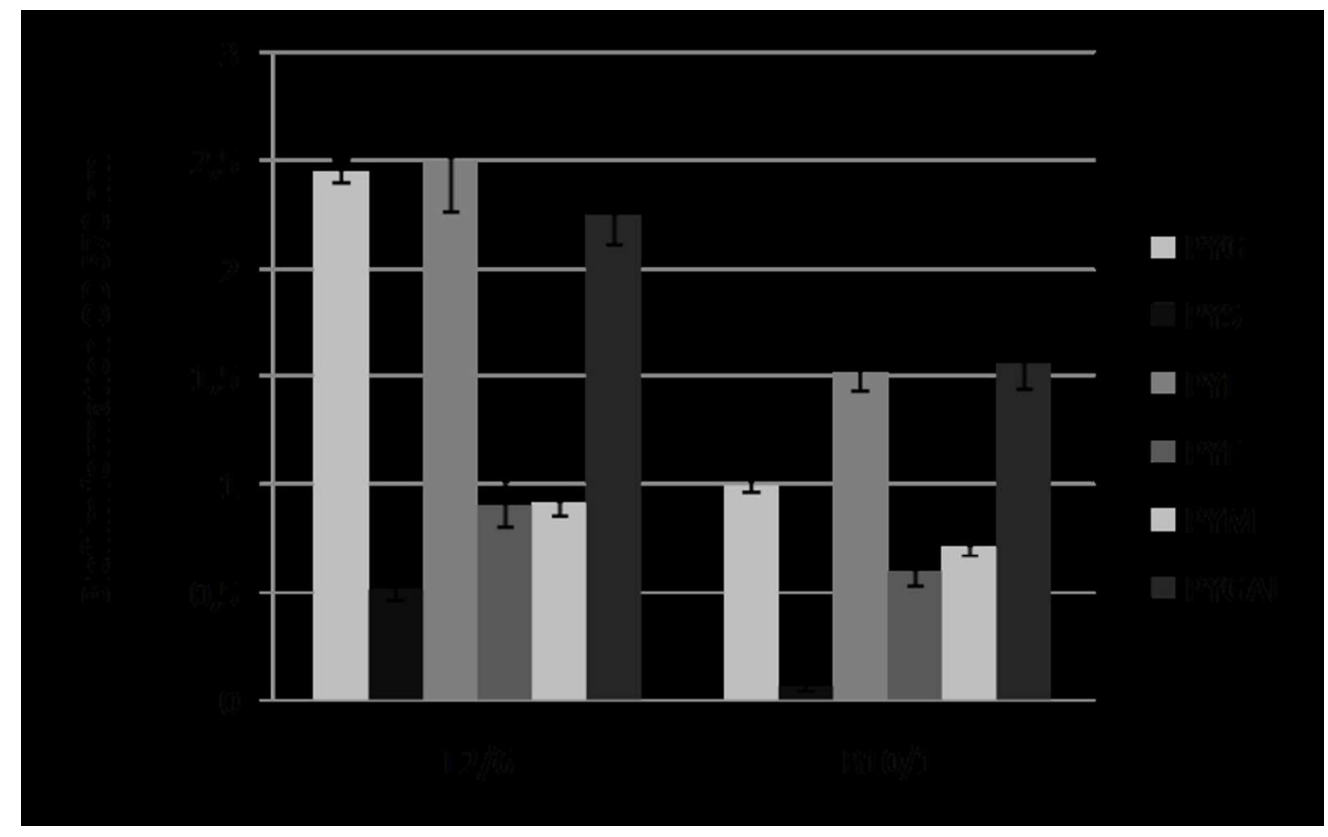

$152 \times 95 \mathrm{~mm}(150 \times 150 \mathrm{DPI})$ 


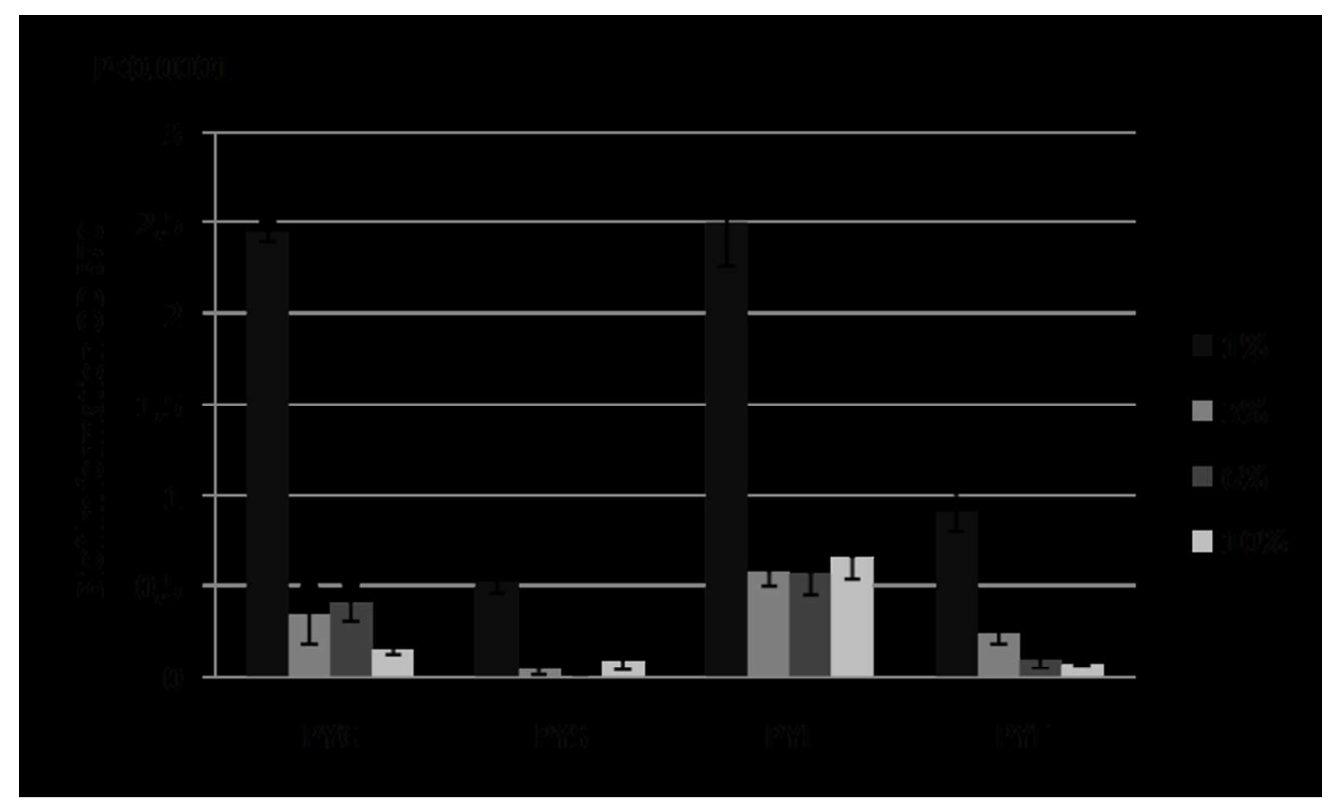

$152 \times 91 \mathrm{~mm}(150 \times 150 \mathrm{DPI})$ 


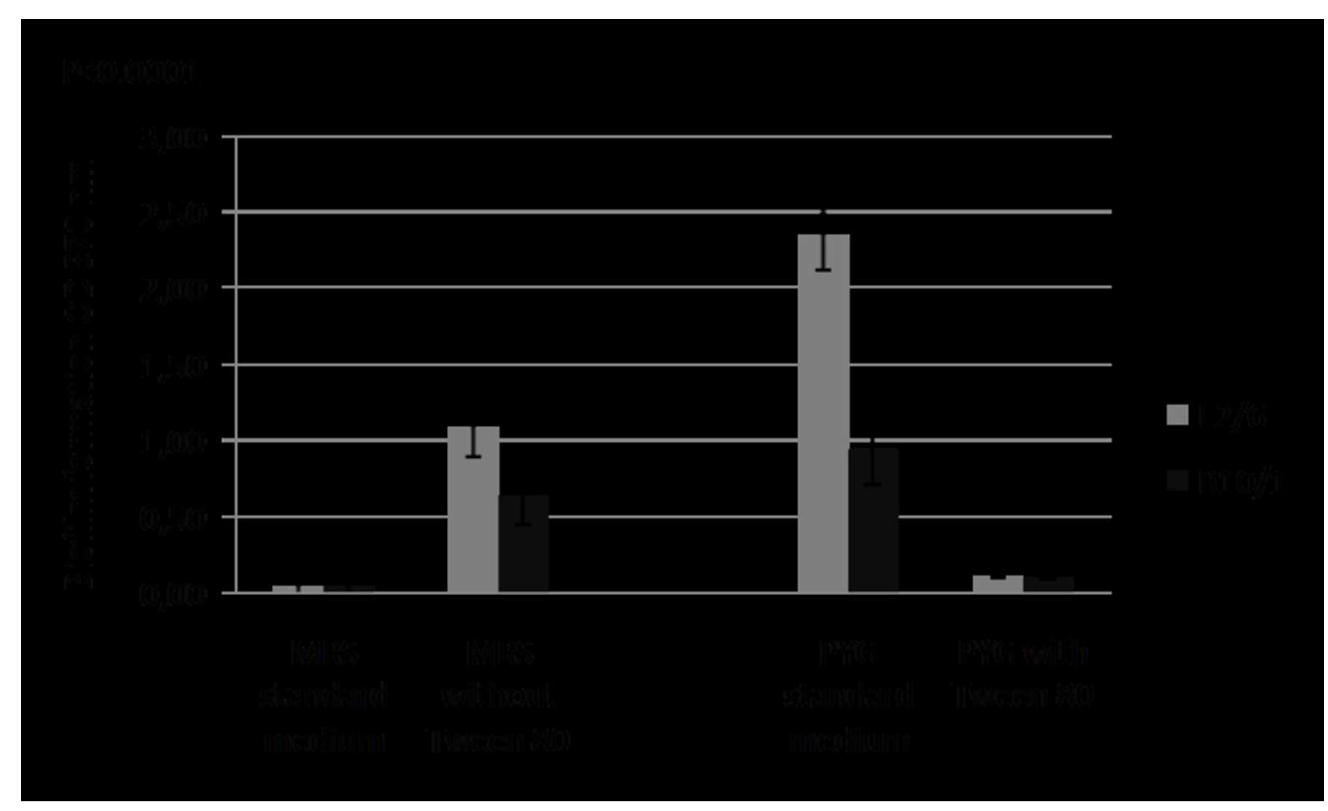

$152 \times 91 \mathrm{~mm}(150 \times 150 \mathrm{DPI})$ 


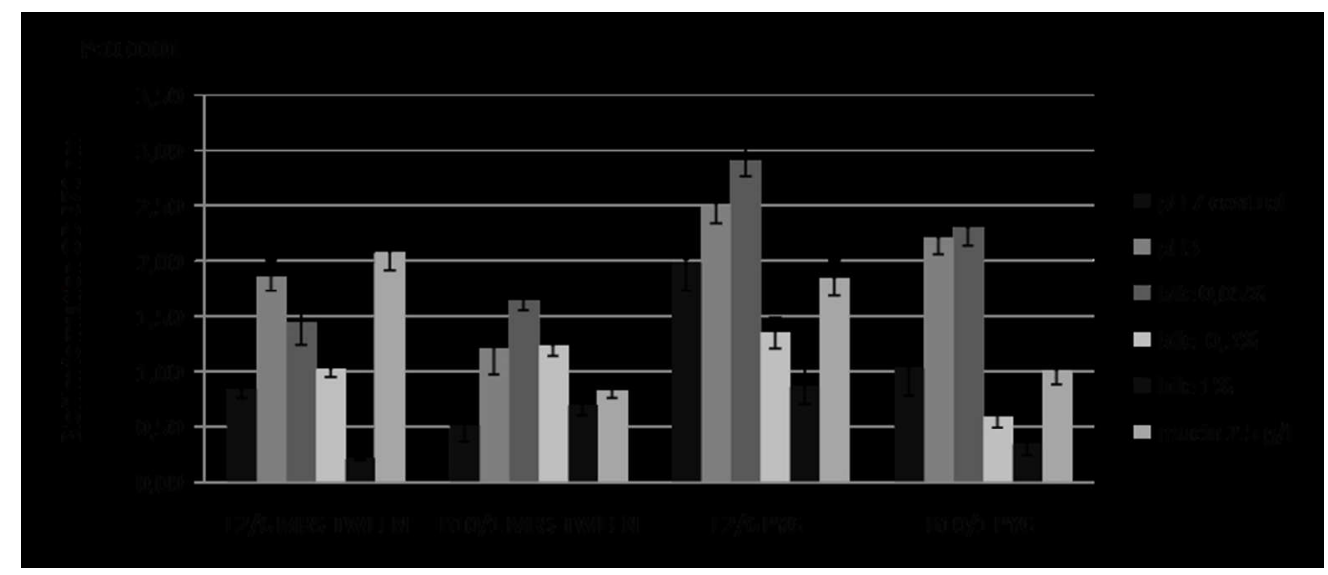

$152 \times 65 \mathrm{~mm}(150 \times 150 \mathrm{DPI})$ 


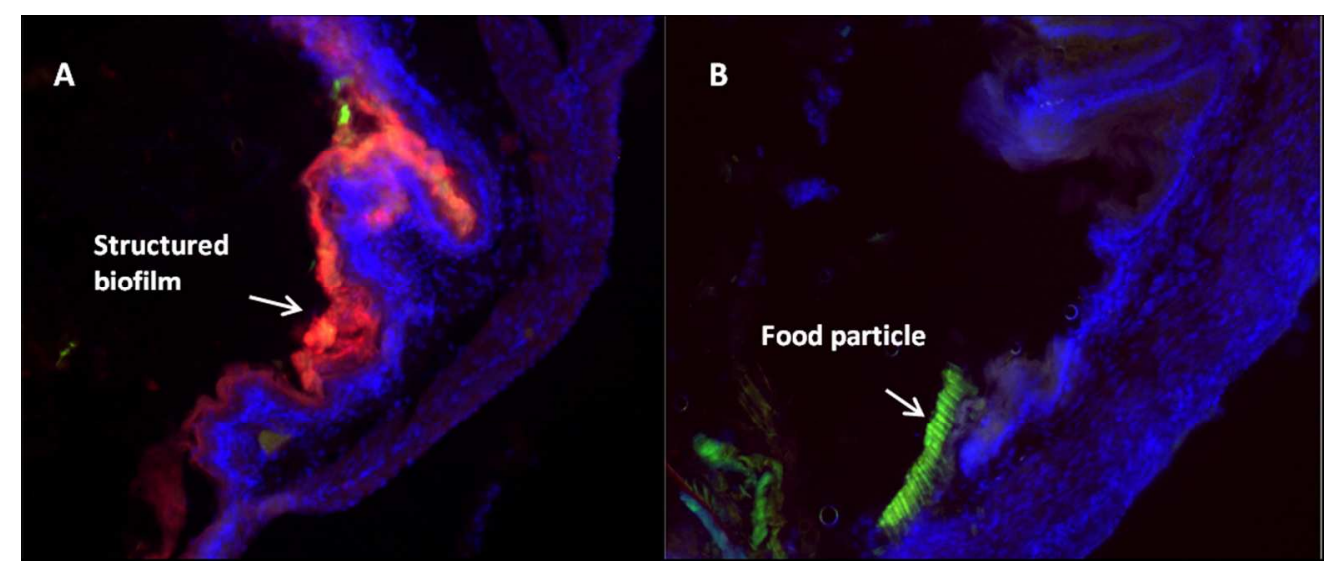

$180 \times 75 \mathrm{~mm}(150 \times 150 \mathrm{DPI})$ 


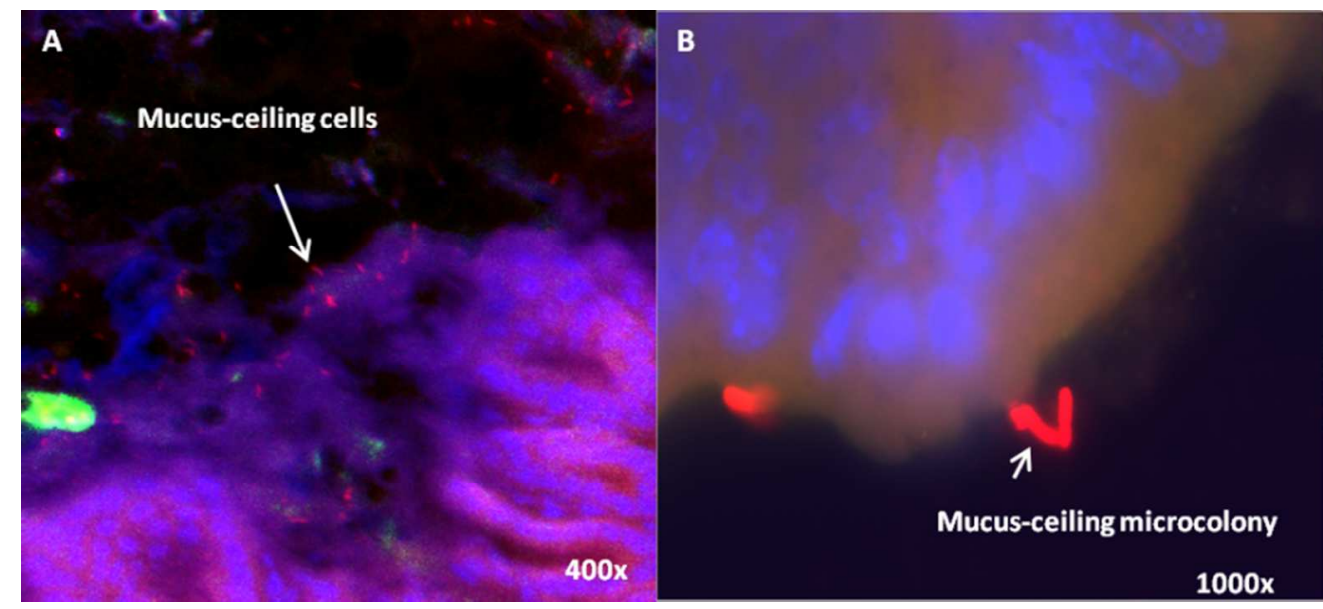

$152 \times 69 \mathrm{~mm}(150 \times 150 \mathrm{DPI})$ 